\title{
An Overview of the Role of Systems Analysis in NASA's Hypersonics Project
}

\author{
Jeffrey S. Robinson ${ }^{1}$ and John G. Martin ${ }^{2}$ \\ NASA Langley Research Center, Hampton, VA \\ Jeffrey V. Bowles ${ }^{3}$ and Unmeel B. Mehta ${ }^{4}$ \\ NASA Ames Research Center, Moffett Field, CA \\ and \\ Christopher A. Snyder ${ }^{5}$ \\ NASA Glenn Research Center, Cleveland, $\mathrm{OH}$
}

\begin{abstract}
NASA's Aeronautics Research Mission Directorate recently restructured its Vehicle Systems Program, refocusing it towards understanding the fundamental physics that govern flight in all speed regimes. Now called the Fundamental Aeronautics Program, it is comprised of four new projects, Subsonic Fixed Wing, Subsonic Rotary Wing, Supersonics, and Hypersonics. The Aeronautics Research Mission Directorate has charged the Hypersonics Project with having a basic understanding of all systems that travel at hypersonic speeds within the Earth's and other planets' atmospheres. This includes both powered and unpowered systems, such as re-entry vehicles and vehicles powered by rocket or airbreathing propulsion that cruise in and accelerate through the atmosphere. The primary objective of the Hypersonics Project is to develop physics-based predictive tools that enable the design, analysis and optimization of such systems. The Hypersonics Project charges the systems analysis discipline team with providing it the decision-making information it needs to properly guide research and technology development. Credible, rapid, and robust multi-disciplinary system analysis processes and design tools are required in order to generate this information. To this end, the principal challenges for the systems analysis team are the introduction of high fidelity physics into the analysis process and integration into a design environment, quantification of design uncertainty through the use of probabilistic methods, reduction in design cycle time, and the development and implementation of robust processes and tools enabling a wide design space and associated technology assessment capability. This paper will discuss the roles and responsibilities of the systems analysis discipline team within the Hypersonics Project as well as the tools, methods, processes, and approach that the team will undertake in order to perform its project designated functions.
\end{abstract}

\section{Nomenclature}

ARMD $=$ Aeronautics Research Mission Directorate

CEV $=$ Crew Exploration Vehicle

CFD $\quad=$ Computational Fluid Dynamics

$\mathrm{DRM}=$ Design Reference Mission

EDL $\quad=$ Entry Descent and Landing

${ }^{1}$ Aerospace Engineer, Vehicle Analysis Branch, M/S 451, AIAA Senior Member.

${ }^{2}$ Aerospace Engineer, Vehicle Analysis Branch, M/S 451, AIAA Member.

${ }^{3}$ Aerospace Engineer, Systems Analysis Branch, M/S 258-1.

${ }_{5}^{4}$ Aerospace Engineer, Space Technology Division, M/S 229-3, AIAA Associate Fellow.

${ }^{5}$ Aerospace Engineer, Aeropropulsion Systems Analysis Office, M/S 500-105. 


$\begin{array}{ll}\text { ESMD } & =\text { Exploration Systems Mission Directorate } \\ \text { FOM } & =\text { Figure-of-Merit } \\ \text { HMMES } & =\text { High Mass Mars Entry Systems } \\ \text { HRRLS } & =\text { Highly Reliable Reusable Launch Systems } \\ \text { HTHL } & =\text { Horizontal Takeoff Horizontal Landing } \\ \text { L/D } & =\text { Lift-to-Drag Ratio } \\ \text { M }_{\mathrm{a} / \mathrm{b}} & =\text { Airbreathing Mach number } \\ \text { NASA } & =\text { National Aeronautics and Space Administration } \\ \text { NGLT } & =\text { Next Generation Launch Technology Program } \\ \text { PB-MDAO } & =\text { Physics Based Multidisciplinary Design Analysis and Optimization } \\ \text { R\&D } & =\text { Research and Technology Development } \\ \text { RBCC } & =\text { Rocket-Based Combined Cycle } \\ \text { SADT } & =\text { Systems Analysis Discipline Team } \\ \text { SBIR } & =\text { Small Business Innovation Research Program } \\ \text { SMD } & =\text { Science Mission Directorate } \\ \text { SSTO } & =\text { Single Stage to Orbit } \\ \text { TBCC } & =\text { Turbine-Based Combined Cycle } \\ \text { TPS } & =\text { Thermal Protection System } \\ \text { TSTO } & =\text { Two Stage to Orbit } \\ \text { VTHL } & =\text { Vertical Takeoff Horizontal Landing } \\ \text { Vo } & =\text { Entry Velocity }\end{array}$

\section{Introduction}

In January 2006, NASA's Aeronautics Research Mission Directorate (ARMD), under the direction of Associate Director Dr. Lisa Porter, announced a reshaping of its programs to focus on the core competencies of aeronautics in all flight regimes, from subsonic to hypersonic ${ }^{1}$. The new directorate is comprised of three programs, the Fundamental Aeronautics Program, the Aviation Safety Program, and the Airspace Systems Program. Each program is comprised of several projects. In the Fundamental Aeronautics Program, now headed by Dr. Juan Alonso, those projects are: Subsonic Fixed-Wing, Subsonic Rotary-Wing, Supersonics, and Hypersonics Projects. Subsequent to the restructuring, each of the projects spent several months putting together five and ten year program plans, schedules, organizational structures, technical task plans, roadmaps, and milestones and submitted these plans to NASA Headquarters in April for approval. The projects have now moved into the implementation phase. The ARMD charges the Hypersonics Project with having a basic understanding of the physics that govern the flight of all systems that travel at hypersonic speeds within Earth's and other heavenly bodies' atmospheres. Today, rocketpowered expendable launch vehicles reach hypersonic speeds in the upper atmosphere while transporting payloads to orbit; low L/D, unpowered hypersonic entry vehicles return to earth from orbit and other heavenly bodies and transit the atmospheres of other planets to land robotic exploration systems; and the Space Shuttle is used to transport humans to low Earth orbit and back. While these are extraordinary accomplishments, hypersonic flight is far from routine, and its potential is not fully exploited.

While many programs have tried, but failed, to produce an operational reusable launch vehicle (National Aerospace Plane Program, X-33, X-34), many advancements in design and analysis tools, test techniques, and understanding of the basic physics of hypersonic flow, materials and structures have been made. Some of these advancements have been applied to the design of other systems (planetary probes) and flight experiments (X-43 and $\mathrm{X}-51$ ), but much is still left to be learned. While there clearly exists the ability to design certain hypersonic systems, designers often resort to large margins to mitigate uncertainties, which reduces system capabilities and increases costs. Uncertainties in propulsion, aerodynamics, aerothermodynamics, material properties, structural response, durability, and integrated system performance have a significant impact on system design and development, mission planning and risk assessment. In addition, substantial deficiencies exist in the ability to predict life cycle cost, safety and reliability of these systems, much less to be able to optimize a system on such metrics. Developing methods and tools that adequately model fundamental physics and allow credible optimization for operational factors is expected to allow highly beneficial hypersonic systems to emerge. A long term commitment of investment in foundational hypersonics research will enable the understanding of the underlying physics sufficient to improve design methods to the level of certainty required to fully utilize the possibilities of hypersonic flight and allow it to become routine. 


\section{Background}

The Hypersonics Project is committed to the objective of understanding the fundamental physics that govern hypersonic flight. The project plans to achieve this objective through research in individual discipline areas, such as propulsion, aerodynamics, aerothermodynamics, controls, and materials \& structures, as well as research in multidisciplinary design and analysis. In addition to improved computational modeling and methods development, experimental data will be gathered through both ground and flight testing. This data will be used to improve and/or validate analytical methods, as well as to augment design databases in all discipline areas. While the potential areas for research in the field of hypersonics are vast, the project has chosen to focus its efforts in support of two primary mission classes. Further discussion of the project organization and the focus of research within the project is given below.

\section{A. Project Overview and Organization}

From a technical perspective, the Hypersonics Project will be organized as shown in Figure 1. At the base (Level 1) are the foundational physics and modeling that support research and technology development (R\&D) activities at the higher levels. Examples of research that would occur at this level include topics such as boundary layer transition modeling (aero / aerothermodynamics), ignition and flameholding (propulsion), and fatigue and crack propagation (materials \& structures). The next level up (Level 2) contains the more traditional discipline level capabilities. This is where propulsion cycle codes, propulsion and aerodynamic computational fluid dynamics (CFD) codes, and structural design and analysis codes are developed. At Level 3, the individual disciplines begin to come together and support subsystem level design and analysis, including multi-disciplinary optimization. For example, the analyses of hot structures (aerothermodynamics coupled with materials \& structures) and flutter (aerodynamics coupled with materials \& structures) are typical Level 3 activities, and the propulsion and airframe systems begin to take shape. At the top (Level 4) lies the overall system design (i.e. vehicle level), where all the subsystem, element, and component models come together and where the principal project objective (to develop systemlevel, physics-based multidisciplinary design, analysis and optimization (PB-MDAO) predictive capabilities) will be accomplished.

To achieve this objective at the system level requires investment in a comprehensive portfolio of $\mathrm{R} \& \mathrm{D}$ activities across all levels. The $R \& D$
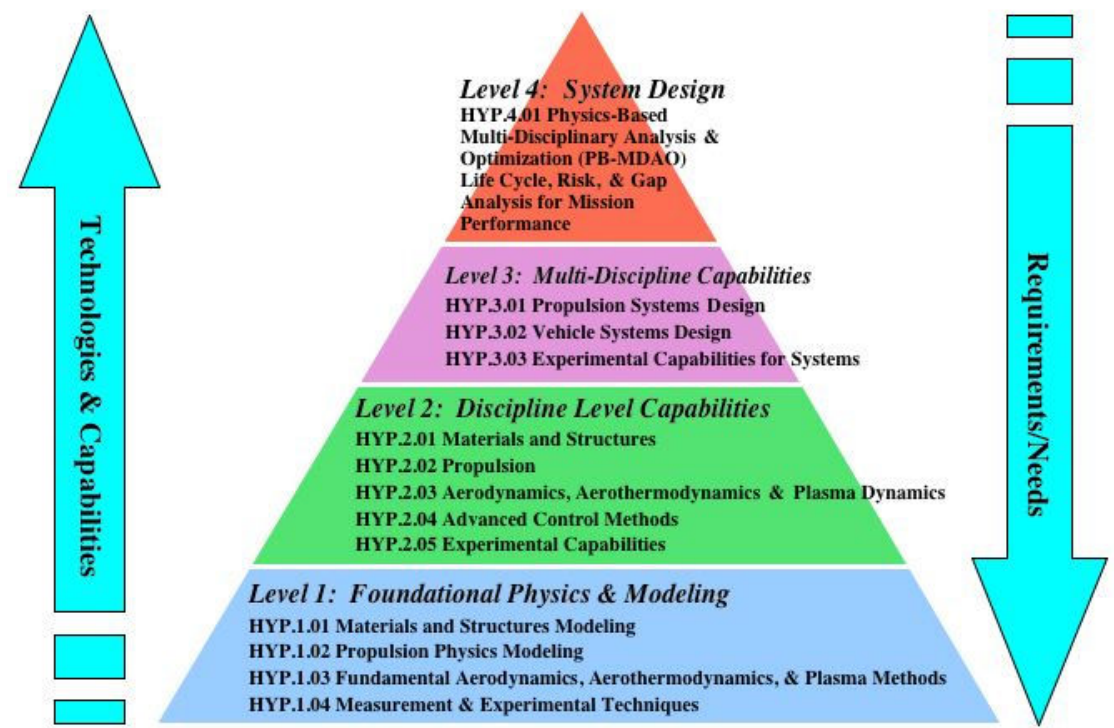

Figure 1. Hypersonic Project multi-level technical organization showing the "push-pull" technology development philosophy.

portfolio is guided by the "push-pull" philosophy where technologies and capabilities flow up to the system level from all the lower levels (Foundational Physics and Modeling, Discipline, and Multi-Disciplinary), while requirements and needs flow down from the system level to the lower levels. For example, at Level 1, research may result in an improved boundary layer transition model. At Level 2, this model could then be incorporated into a CFD code yielding a more accurate heat transfer prediction capability. At Level 3, this improved CFD analysis can then be coupled with a thermal protection system (TPS) sizing code to analyze and predict the TPS material distribution and thicknesses required for a specific reference vehicle and mission. The reduced uncertainty in this analysis then translates into lower required design margins, resulting in increased system capability or reduced system size and weight for the same capability at Level 4 . In a similar but reverse fashion, a need at the system level can flow down to a technology or improved methodology requirement at the lower levels. 


\section{B. Taxonomy and Reference Missions}

Figure 2 presents a portfolio of potential "vision" entry, ascent, and cruise systems that transit the hypersonic flight regime. The major system characteristics are briefly described for selected entry missions such as crew exploration vehicle (CEV) and planetary entry vehicles for Mars, giant planets, and large satellites; for advanced reusable space access missions such as airbreathing two-stage-to-orbit (TSTO) vehicles and single-stage-to-orbit (SSTO) vehicles; and for cruise systems such as strike and global reach vehicles. In addition to having ascent segments, the space access SSTO vehicles and TSTO vehicles also include entry, descent, and landing (EDL) segments. In addition, the airbreathing vision systems are further categorized in Figure 2 by scramjet operational Mach number, or maximum airbreathing engine Mach number $(\mathrm{Ma} / \mathrm{b})$; whereas the pure entry systems are categorized by entry velocity $\left(\mathrm{V}_{\infty}\right)$ in $\mathrm{km} / \mathrm{s}$. These speed regimes along with the mission class of the vision system tend to define the technologies and design methods required, but there is also significant overlap in technologies and methods between mission classes and/or speed regimes. The Hypersonics Project plans to take advantage of this commonality to address as many critical technologies and design methods as possible by focusing on two high payoff NASA unique missions which cover much of this space.

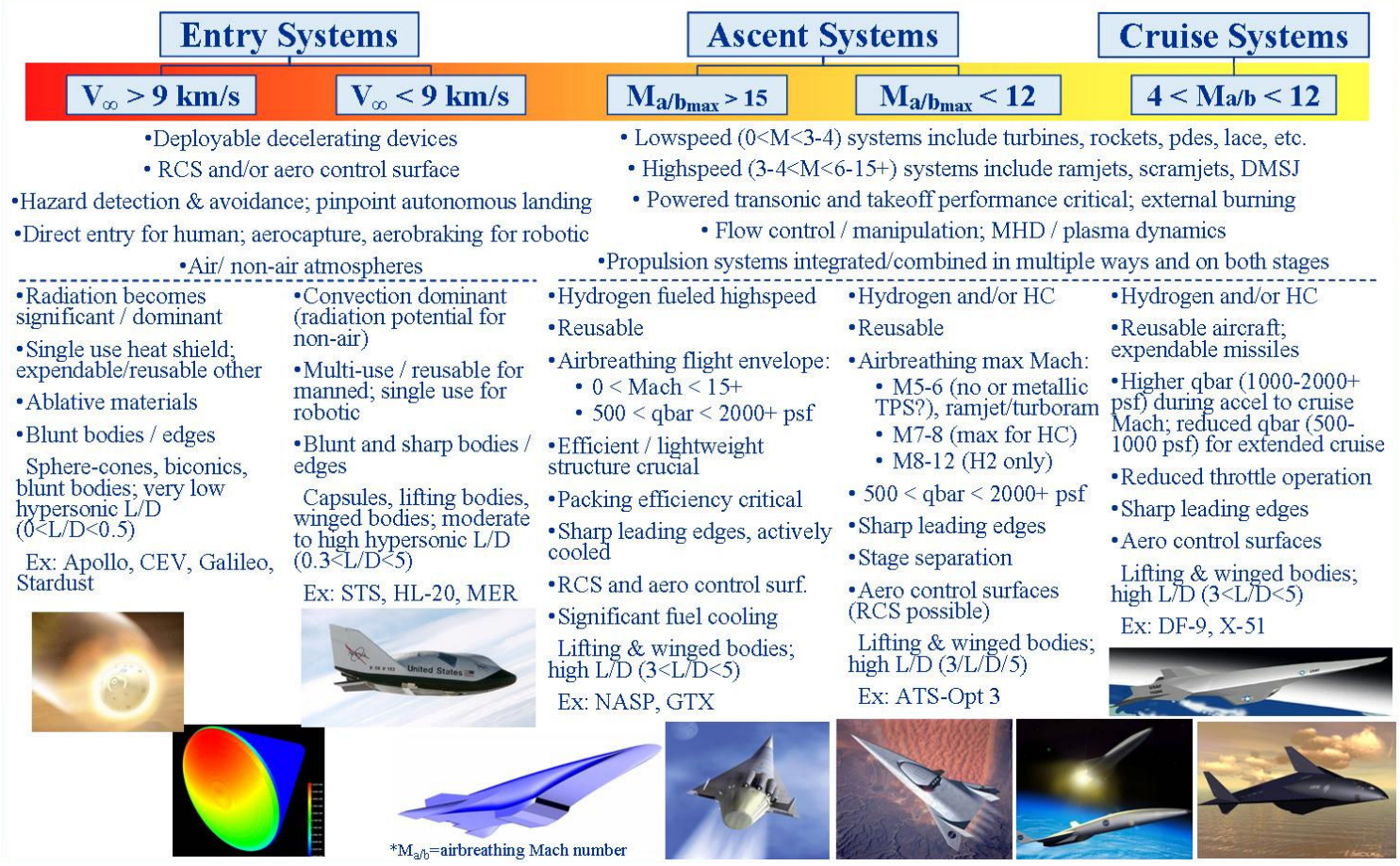

Figure 2. Portfolio of potential "vision" entry, ascent, and cruise hypersonic cruise systems.

The two specific mission classes that have been chosen by the Hypersonics Project to focus technology and methods development efforts are Highly Reliable Reusable Launch Systems (HRRLS) and High Mass Mars Entry Systems (HMMES). These two mission classes address the technology and methods needs shown on the second and fourth columns of Figure 2. Each addresses an area critical to future NASA needs while providing a basis for the more challenging technology and methods development work represented in the other three columns. Specific high pay-off technologies from these more challenging mission classes will be pursued such as shock layer radiation modeling from column one and hypervelocity combustion physics from column three.

The HRRLS mission class was chosen to build on work accomplished in the Next Generation Launch Technology (NGLT) Program, which aimed to provide new vehicle concepts and architectures in order to dramatically increase the reliability of launch vehicles. The current state-of-the-art for reliability of launch vehicles is approximately 1 loss in 50 missions for expendables and less than 1 in 100 for manned systems such as the Space Shuttle. These low reliability numbers reduce the market for launches and thus increase the cost of launching cargo and people to orbit. The NGLT Program spent considerable resources over several years studying a wide variety of future launch vehicle concepts including vertical take-off horizontal landing (VTHL) all rocket systems, horizontal take-off horizontal landing (HTHL) and VTHL rocket-based combined cycle (RBCC) systems, and HTHL turbine-based combined cycle (TBCC) systems ${ }^{2}$. When reliability was used as the figure of merit (FOM) to compare these vehicle types, 
airbreathing systems out performed all rocket systems by orders of magnitude ${ }^{3}$. These reliability improvements were a result of higher efficiencies of the airbreathing systems allowing higher inert mass fraction to increase structural and systems margins so safety could be designed in. In addition, the HTHL systems also had more abort options available due to their high $\mathrm{L} / \mathrm{D}$. While the exact magnitude of the improvements indicated in these study results can be questioned, the trends and the obvious potential for large reliability improvements due to airbreathing propulsion systems are clear.

The HMMES mission class was chosen as a second focus of the project because dramatic improvements in our capability to safely land large payloads on Mars are required in order to enable large science and human exploration missions. The state-of-the-art for successfully landing payloads on Mars is less than one metric ton with an accuracy of approximately a $100 \mathrm{~km}$ footprint around the target. Recent studies ${ }^{4,5}$ have shown that the current technology, which was developed for the Viking Landers in the 1970s, cannot be extended to payload masses much beyond one metric ton. Plans for human and large science missions to Mars require nearly two orders of magnitude increase in mass landed safely, and targeting improvements of three to four orders of magnitude. The crux of the problem is that the Mars atmosphere is thick enough to cause significant thermal heating, but so thin that terminal velocities are very high. These factors combined with the need for precise targeting requirements to enable landing at points of scientific interest and/or rendezvous with prepositioned assets cause daunting challenges for the system designer. Solving the problem of safely landing large payloads on the surface of Mars requires analysis of a number of technology options over the entire EDL speed range from high hypersonic to subsonic speeds. The Hypersonics Project will work with technologists supported by Exploration Systems Mission Directorate (ESMD) and Science Mission Directorate (SMD) to undertake a systems analysis trade study aimed at identifying the decelerator approaches with highest likelihood of success, and identifying key hypersonic technologies and modeling challenges that require further work. This study along with a number of well known technology and modeling needs for entry vehicles form the basis of the proposed work supporting entry vehicle technology.

\section{Systems Analysis Roles and Responsibilities}

As mentioned, the primary objective of the Hypersonics Project is to expand our scientific and engineering knowledge base of all hypersonic-related aeronautics challenges. The principal goal of this endeavor will be the development of physics-based multi-disciplinary predictive design, analysis and optimization tools. While broad enough to analyze any of the systems and missions represented in Figure 2, these tools will be focused on supporting the two primary missions established by the Project, HRRLS and HMMES. The principal challenges in achieving this goal for the Systems Analysis Discipline Team (SADT), who is responsible for planning and executing activities at Level 4, are the introduction of high fidelity physics into the multi-disciplinary analysis process and integrated design environment. Other key challenges include the quantification of uncertainty in design through probabilistic methods, reduction in design cycle time, and the development and implementation of robust processes and tools enabling a wide design space and associated technology assessment capability. The SADT is responsible for providing the Hypersonics Project with the decision-making information it needs to properly guide technology and analytical tool development. Credible, rapid, and robust system analysis processes and design tools are required by the SADT in order to generate this information.

In addition to improving our analytical processes and design tools, the SADT performs several major functions for the Hypersonics Project which help to provide the project with data used to guide the research and technology development at the lower levels within the project. These functions include the development of relevant reference missions and vehicle concepts from which technology requirements can be derived and passed to other discipline teams to serve as goals for their technology development efforts. These same reference vehicles are also used to track technology development progress and assess our projected ability to meet stated goals for mission performance and other FOMs. To accomplish this work, the SADT will work toward an annual cycle of systems analysis that includes reviewing, updating and adding missions and reference vehicles, adding increased fidelity to existing concepts in order to drive out technology requirements to the subsystem and component levels, continued discipline tool and integrated environment development, and technology assessment, prioritization, and gap identification, as well as other project support (e.g. roadmapping activities for technology development and required experiments). These tasks are described in more detail below.

\section{A. System Studies and Reference Vehicle Development}

The SADT will support the HRRLS and HMMES mission classes by developing a specific Design Reference Mission (DRM) for each class. The DRMs will contain specific performance related requirements as well as information on what FOMs should be used to evaluate the reference concepts. For example, for the HRRLS mission, 
a DRM may contain requirements such as launch and landing latitude and longitude, orbital destination (apogee, perigee and inclination), mission duration and frequency, payload upmass and downmass requirements, on-orbit maneuvering requirements, etc. The DRM would also list FOMs against which the reference concept should be evaluated. Potential FOMs might include turnaround time (for a highly responsive concept), loss of mission or loss of vehicle (for a reliable or robust concept), development cost, life cycle cost, etc.

As mentioned, the SADT will work with engineers from ESMD and SMD to perform systems analysis trade studies for the HMMES mission class. These studies and resulting system concepts will be aimed at identifying the decelerator approaches with highest likelihood of success, and identifying key hypersonic technologies and modeling challenges that require further work. Some initial concepts for hypersonic decelerators are shown in Figure 3. In the upper right is the current state-ofthe-art Viking type system. The upper left image shows a large inflatable ring structure. The lower right shows a large deployable conical shaped aeroshell that could either be inflatable or possibly a lightweight high-temperature rigid structure. The lower left image shows a simpler, moderate L/D design. Previous studies have indicated that, in general, desirable characteristics for these types of systems include high drag, low heating, the ability to modulate L/D, efficient packaging, and

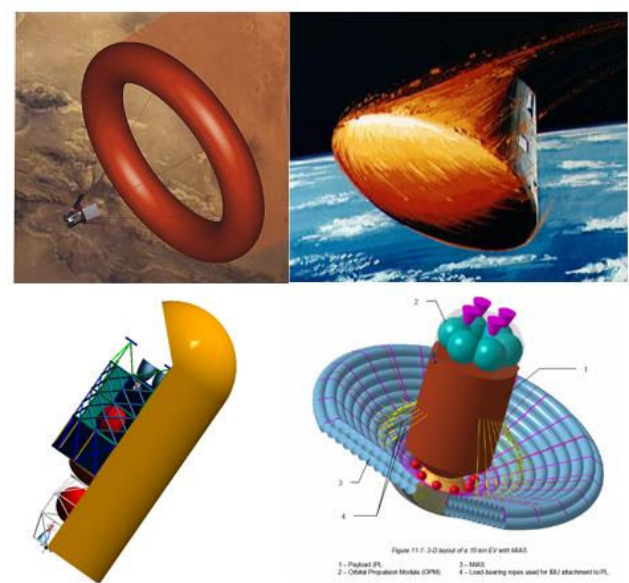

Figure 3. Initial design concepts to the HMMES mission class. aerodynamic stability in all flight regimes.

For the HRRLS mission class, initial work will focus on the continued development of the most promising class of concept resulting from the NGLT studies, a turbine-based TSTO system that employs HTHL operations, like the one shown in Figure 4. Updated vehicle definitions with expendable and reusable upper stages will be developed, and a more detailed analysis of the vehicle's transonic and takeoff performance will be completed. These areas have significant impact on the overall system design but historically have not been analyzed in great detail because of the complexity of the analysis and more of a focus on propulsion performance. A detailed analysis of the propulsion systems performance, mechanical, structural, and thermal design will be performed. A series of trade studies including fuel choices, staging Mach number, and the level of technology advancement assumed will be examined. In addition, an assessment of system sensitivity and robustness will be made though a probabilistic uncertainty analysis.

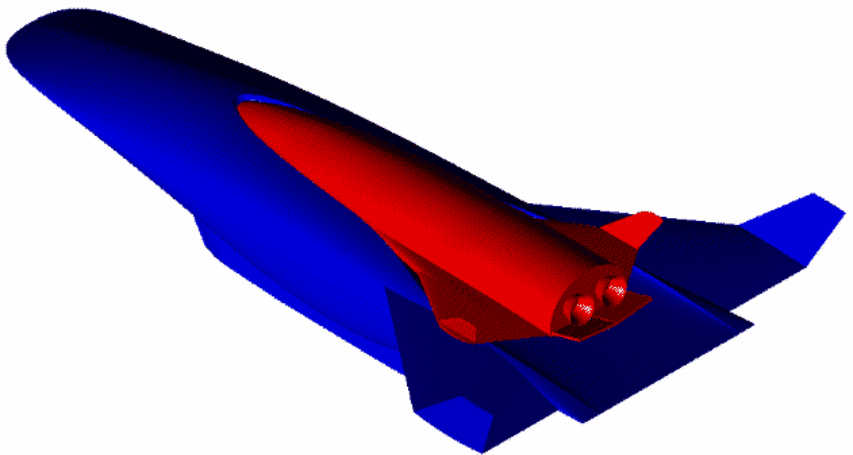

Figure 4. Two stage to orbit concept in support of HRRLS mission class.

\section{B. Technology Assessment}

While the system studies and reference vehicle development tasks refine concept designs, define system requirements, and identify the necessary enabling capabilities, the technology assessment process evaluates systemlevel impacts of given research pursuits and technologies and provides research and technology investment strategies through systems analysis. It identifies investment opportunities to maximize performance and robustness while minimizing cost and risk. The primary objectives of the technology assessment effort are first to develop and maintain a database containing technical and programmatic data on relevant research and technologies for the Hypersonics Project and secondly to develop and implement research and technology impact analysis and assessment tools and methodologies.

Benefits derived from achieving the primary objectives are numerous. They include: (1) the ability to perform regular and structured research and technology assessment for vision systems of interest from a known analytical basis; (2) improved long-term, strategic planning; (3) the ability to perform quick turn-around analysis; and (4) the ability to represent research and technology portfolio status in a meaningful and easily understood manner. It is important to note that this technology assessment process will evolve over time. The depth and breadth of the 
analyses will also increase over the next several years as systems and architectures are refined and the system analyses process becomes more automated.

The overall research and technology assessment process includes three key tasks: (1) collect and develop key data on research and technologies relevant to the system concept of interest and populate a database in order to facilitate research and technology impact assessment and portfolio analysis; (2) perform system sensitivity analysis to quantify impact of these research and technology pursuits against key capability metrics (FOMs, utility, etc.) to produce a set of prioritized research and technology investment options; and (3) perform sensitivity analysis and trades on the research and technology investment portfolio to evaluate the impact constraints such as budget, schedule, and risk. The first task is the development of a comprehensive research and technology and mission / system concept database that focuses on planned, programmed, and budgeted R\&D resources and activities within the United States. Through this database and associated analyses, NASA will obtain cross-cutting, easily accessible information on research and technology development occurring both within and outside of the agency to leverage efforts, fill capability gaps, and avoid duplications.

\section{Tool and Method Development}

Being able to accurately model, analyze and optimize the high level of discipline coupling and integration that is characteristic of hypersonic systems is the key to unlocking their performance potential. In order to achieve a credible vehicle design, a highly interactive collaborative design and analysis environment populated by disciple analysis tools, like those shown in Figure 5, is critical. All technical disciplines must be represented, preferably with a high degree of automation and information transfer implemented. These individual technical discipline tools must also be balanced in the sense of depth of analysis and fidelity levels, such that a consistent vehicle design is achieved. Note that the "Life Cycle Analysis" element in Figure 5 includes cost, reliability, safety, and related operational disciplines.

Top level requirements for this environment include support of a collaborative inter-disciplinary tool suite.

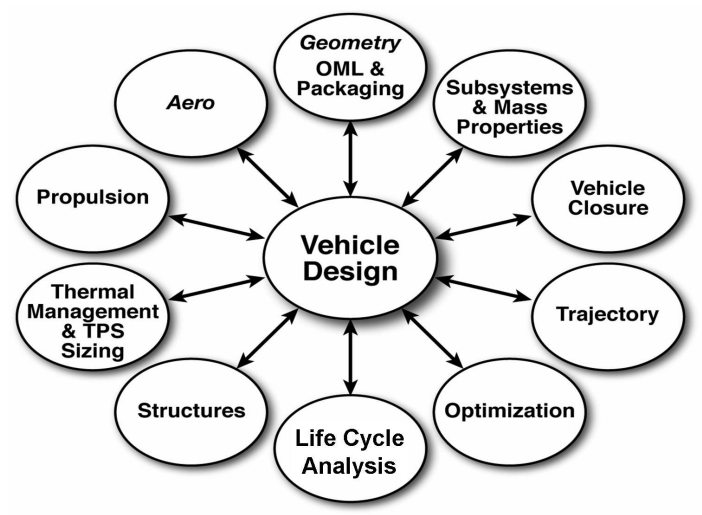

Figure 5. Schematic showing some of the disciplines involved in hypersonic vehicle design that must be integrated into design environment.

Functions include parametric geometry generation, streamlined data transfer between analysis tools, automated coupling and execution of computational analyses, multi-disciplinary design optimization methods, and probabilistic methods and processes that enable system level risk assessment / mitigation and robust vehicle configuration optimization. The goal is to bring this environment on-line in the third year of the project, and then work to improve its efficiency, accuracy, and robustness. The SADT plans to continue work on the development of an integrated design, analysis and optimization environment $^{6}$ that will incorporate increasingly higher fidelity tools, including those tools developed by the Level 1 ,

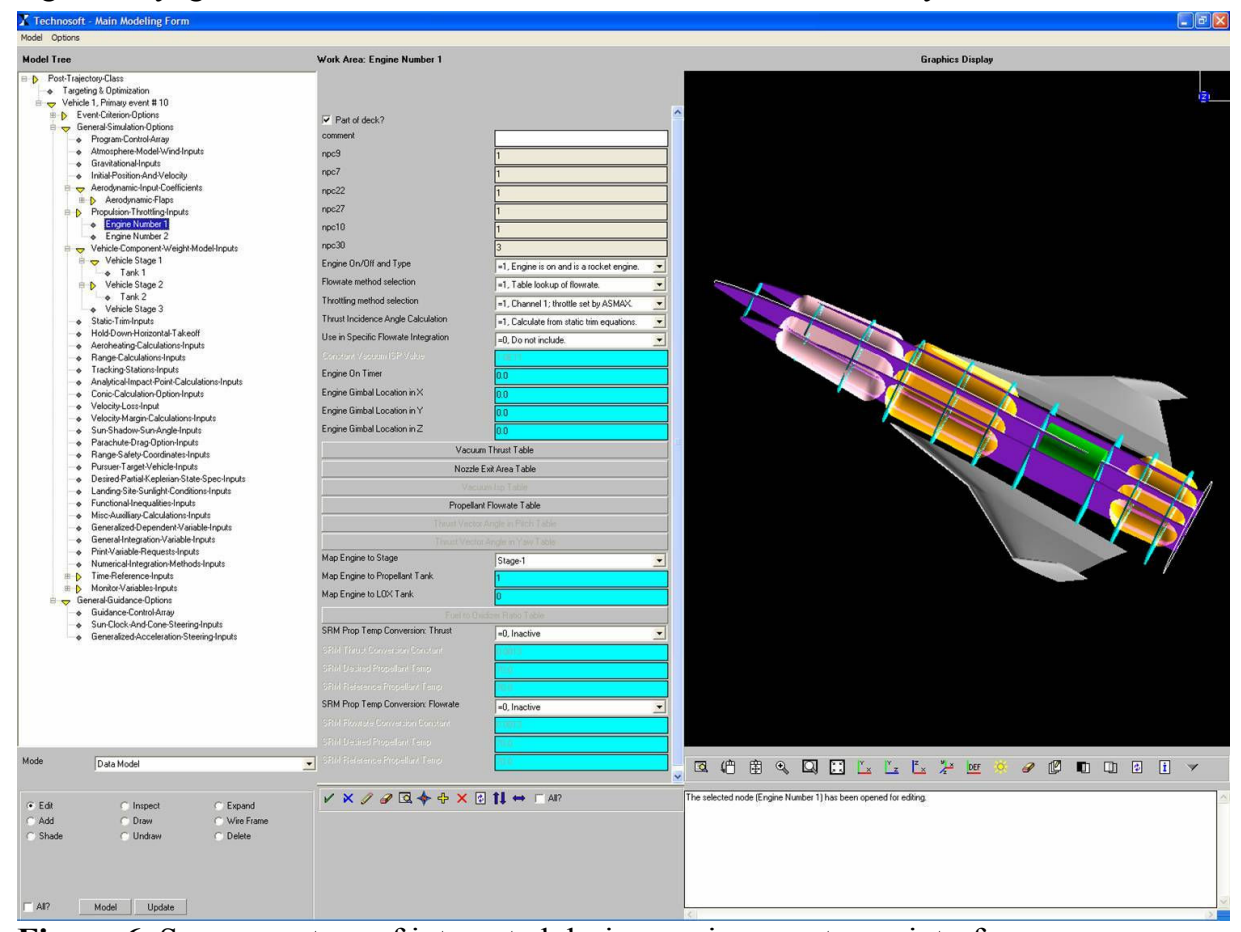

Figure 6. Screen capture of integrated design environment user interface. 
2 and 3 discipline teams. A significant amount of development has already been completed on this environment. A snapshot of one of the interfaces is shown in Figure 6. The SADT will also incorporate techniques focused on multidisciplinary design optimization methods incorporating uncertainties?

The SADT will also work to improve the fidelity of their Level 4 specific tools. These include system safety and reliability models, life cycle cost models, airframe and propulsion subsystem models, and vehicle closure, synthesis, and sizing. The SADT currently has plans to upgrade their launch vehicle safety and reliability tool to encompass advanced hypersonic designs. The SADT is working with the Level 2 propulsion discipline team to upgrade our scramjet weights and sizing model. In addition, the SADT will work with teams from Levels $2 \& 3$ to develop advanced CFD-based planform and vehicle shaping design capability allowing for the design of more threedimensional (from a fluid dynamics perspective) vehicle and integrated propulsion system concepts.

\section{Annual Process and Plans}

The SADT plans to divide the time its researchers spend on each of its three major tasks: system studies, technology assessment, and tool \& method development. The tool and method development is expected to be a continuous year-round effort consuming roughly one third of the total workforce time. System studies and technology assessments are expected to occur serially, with roughly six to eight months being spent on system studies and the remaining four to six months of the year spent performing technology assessment. At the end of the technology assessment effort, the SADT will hold a project wide review of our process and findings. This annual review will serve several purposes. First, by exposing our integration and evaluation process for each technology examined, stakeholding researchers can provide feedback as to potential modeling improvements that would render the process and results more accurate. Secondly, such interaction between the levels could easily result in new ideas for technologies, new applications of technologies, or new vehicle concepts that may take better advantage of certain technologies. The review also serves to provide project management an excellent venue to assess the state of technology development and progress within the project, as well as providing information that management can use to make funding decisions, if required.

In coordination with the Hypersonics Project Level 1, 2 and 3 teams, the SADT will establish an annual, projectwide review of analytical tools in order to track their development, validation, and uncertainty reduction progress. This review will be held at the end of the system study and vehicle development effort, prior to the beginning of the technology assessment process. During this review, new shortfalls in analytical capability may be identified while existing deficiencies may have been eliminated during the previous year by bringing new capabilities on-line. In addition, uncertainty levels for each of the level 4 tools will eventually be quantitatively assessed through validation.

Before this regular annual cycle of analysis can proceed, there are several tasks that need to be undertaken first. These include a review of the current suite of Level 4 analytical tools, their fidelity levels and identification of gaps or shortcomings that may exist, the definition of the hypersonic design space to be addressed, the development of an initial set of design reference missions and vehicles within the two mission classes, and a detailed process plan for the annual cycle. These items have been identified as key milestones for the SADT to complete by the end of the first quarter of FY07. The regular annual analysis cycle will then commence with a technology assessment effort beginning the second quarter of FY07.

One of the first tasks will be to review the existing suite of zeroth and first-order tools currently used to perform conceptual hypersonic vehicle design and analyses and to identify any gaps or inadequacies that may be present. Hypersonic vehicles are highly integrated systems with unprecedented levels of interdisciplinary interactions involving a broad spectrum of technologies and technical disciplines. The tool suite employed by the SADT must encompass this breadth of technical disciplines and higher order FOM tools and be able to accommodate the increased scope of configurations and concepts set forth in Figure 2. Starting in 2007 and continuing for several years, efforts to upgrade and enhance these tools, particularly the higher order FOM tools, will be undertaken to address the broad range of hypersonic vehicle configurations and concepts. In coordination with the other discipline teams, the SADT will review the state-of-the-art in the higher fidelity analysis tools. This effort will be a precursor to the long-term goal of integrating higher fidelity tools and methods into the design and analysis environment. This will require an ever-increasing level of integration and data exchange between the tools, but will eventually result in initial conceptual designs that have much lower levels of uncertainty and higher performance capability than are currently possible.

\section{Summary}

In summary, an overview of the newly formed Hypersonics Project within NASA's recently restructured Aeronautics Research Mission Directorate was provided, detailing its technical organization structure as well as the 
focus of its research and technology development efforts. The roles and responsibilities of the systems analysis discipline team within the project were discussed. These include performing system studies and developing reference vehicles from which technology requirements can be derived, performing technology assessments on these reference vehicles in order to measure technology development progress and our projected ability to meet stated goals and missions, and improving our suite of analytical tools and integrated design environments. The annual process that the systems analysis discipline team will follow was also detailed, including a description of some of the annual project-wide reviews that will be held.

\section{References}

1 "A Re-Shaped Aeronautics Program"; 44 ${ }^{\text {th }}$ AIAA Aerospace Sciences Meeting, Reno, NV, January 2006. $\mathrm{http} / / / \mathrm{www}$.aero-space.nasa.gov/reshaped_program.htm

${ }^{2}$ NGLT Systems Analysis Tiger Team Study Results: Implications for Space Launch Architectures and Technologies; V. Bilardo, J. Robinson, NASA Langley, Hampton, VA; D. Komar and W. Taylor, NASA Marshall, Huntsville, AL; N. Lovell and G. Maggio, Science Applications International Corporation, Huntsville, AL; AIAA-2003-5263; 39 ${ }^{\text {th }}$ AIAA/ASME/SAE/ASEE Joint Propulsion Conference, Huntsville, AL, July, 2003.

${ }^{3}$ The Benefits of Hypersonic Airbreathing Launch Systems for Access to Space; F. Curran, J. Hunt, N. Lovell and G. Maggio, Science Applications International Corporation, Huntsville, AL; V. Bilardo, NASA Langley, Hampton, VA; AIAA-2003-5265; 39 ${ }^{\text {th }}$ AIAA/ASME/SAE/ASEE Joint Propulsion Conference, Huntsville, AL; July, 2003.

4 "Mars Exploration Entry, Descent and Landing Challenges" Braun and Manning; IEEE Paper 06ID0076; http://hdl.handle.net/1853/8390.

5 “The Mars EDL Problem" Powell, et al, presentation to the NASA Engineering Management Board; April 4, 2006.

${ }^{6}$ Developing Conceptual Hypersonic Airbreathing Engines Using Design of Experiments Methods; Ferlemann,S.M., Robinson,J.S., Leonard,C.P., Taylor,L.W.III, Martin,J.G. and Kamhawi,H.; AIAA 2000-2694; $21^{\text {st }}$ Advanced Measurement Technology and Ground Testing Conference, Denver, CO; June, 2000.

${ }^{7}$ Multi-Disciplinary Design Optimization under Uncertainty for Thermal Protection System Applications ; J. Sun and G. Zhang, Michigan Engineering Services, Ann Arbor, MI; N. Vlahopoulos, University of Michigan, Ann Arbor, MI; and S. Hong, Cummins, Columbus, IN; AIAA-2006-7002; $11^{\text {th }}$ AIAA/ISSMO Multidisciplinary Analysis and Optimization Conference, Portsmouth, Virginia, September, 2006. 